\title{
A REDUÇÃO DA MAIORIDADE PENAL E A REALIDADE NÃO ENFRENTADA
}

Lucas Ferreira Furlan, Sérgio Mastellini

Universidade do Oeste Paulista - UNOESTE, Curso de Direito, Presidente Prudente, SP. E-mail: lucasfurlan94@hotmail.com

\section{RESUMO}

No presente artigo foi apresentado um estudo acerca da atual situação que circunda o debate a respeito da redução da maioridade penal no Brasil. Inicialmente foi construído um levantamento a respeito da função das penas, posteriormente foi analisado as atuais punições destinadas aos menores em nosso país, bem como os problemas estruturais que tem impedido uma completa aplicação do ECA, aos casos a ele submetidos, em seguida fizemos uma analise no direito comparado a respeito da redução da imputabilidade penal, seguido do estudo de sua inconstitucionalidade. Ao final apresentamos uma pequena alteração no ECA como solução para os menores infratores de periculosidade elevada, demonstramos como os investimentos em educação são a melhor alternativa para solucionar o problemas e encerramos com as nossas conclusões a respeito do assunto.

Palavras Chave: Redução, Menor, Medidas, Legislação e Internação.

\section{THE REDUCTION OF MAJORITY CRIMINAL AND REALITY NOT DEBATED}

\begin{abstract}
In this article we presented a study on the current situation surrounding the debate about reducing the legal age in Brazil. Initially it was built a survey about the role of penalties, was later analyzed the current punishments designed smaller in our country as well as the structural problems that have prevented full implementation of ECA the cases it hears, then did an analysis in comparative law regarding the reduction of criminal responsibility, then the study of its unconstitutionality. At the end we present a small change in ECA as a solution to juvenile offenders of high dangerousness, we demonstrate how investments in education are the best alternative to solve the problems and we end with our conclusions on the matter.
\end{abstract}

Keywords: Key, Minor, Measures, legislation and hospitalization. 


\section{INTRODUÇÃO}

Sempre que algum crime de grande clamor social é cometido por algum menor ou simplesmente envolvendo algum, parcelas da sociedade se movimentam no sentido de tentar reduzir a maioridade penal, atualmente isto não ocorreu, mas novamente, vemos em um debate totalmente carente de coerência o Congresso fazer andar a PEC que tentará reduzir a idade da imputabilidade penal.

Neste artigo apresentaremos um estudo com o objetivo de analisar as causas que tem impedido a correta aplicação do Estatuo da Criança e do Adolescente, bem como apontaremos as possíveis soluções não só para o combate da criminalidade infantil como um todo, mas também daqueles menores que apresentam periculosidade elevada.

\section{METODOLOGIA}

$\mathrm{O}$ artigo foi norteado por pesquisas bibliográficas, leituras e fichamentos. Os dados foram analisados com emprego do método hipotético-dedutivo, informações coletadas analisadas e confrontadas de forma dialética.

\section{RESULTADOS}

Os resultados alcançados com a presente pesquisa foram concretos, de forma a contribuir de modo racional e equilibrado para o debate que trata da redução da maioridade penal no Brasil.

\section{DISCUSSÃO}

\section{A Função das Penas}

Antes de adentrarmos na especifica questão da redução da imputabilidade penal, entendemos ser necessário um rápido estudo sobre as reais funções das penas bem como se estas estão sendo alcançadas.

O Código Penal Brasileiro através de seu artigo 59 determina que as penas devam ser aplicadas de forma suficiente a reprovar e prevenir o crime. Destarte nossa legislação entende que a pena deve não somente reprovar a infração cometida pelo agente, mas bem como impedir que novas condutas delitivas se concretizem.

A respeito dos objetivos das penas duas teorias se destacaram, a absoluta que entende ter a pena o simples caráter de retribuição do mal praticado e a relativa que advoga a tese da prevenção.

A respeito da teoria Absoluta ensinanos Roxin (Apud GRECO 2012, p. 473):

A teoria da retribuição não encontra o sentido da pena na perspectiva de algum fim socialmente útil, senão em que mediante a imposição de um mal merecidamente se retribui, equilibra e expia a culpabilidade do autor pelo fato cometido. Se fala aqui de uma teoria "absoluta" porque para 
ela o fim da pena é independente

"desvinculado" de seu efeito social. A concepção da pena como retribuição compensatória realmente já é conhecida desde a antiguidade $\mathrm{e}$ permanece viva na consciência dos profanos com uma certa naturalidade: a pena deve ser justa e isso pressupões que se corresponda em sua duração e intensidade com a gravidade do delito, que o compense.

É perceptível que a massa populacional em geral se contenta com este simples objetivo penal, até pelo fato deste ser de simples compreensão, assim como fez será punido, o grande problema é que a simples punição não assegura a sociedade de que novos delitos não serão praticados, com o intuito de sanar esta falha surgiram às teorias Relativas ou Preventivas.

O objetivo destas teorias é fazer com que as penas possuam um duplo efeito, quais sejam, geral e especial, sendo estes entendidos em sentido positivo e negativo, assim vejamos, a Teoria da Prevenção Geral em sentido negativo, entende que a pena deve atuar como meio de intimidação social e com isso impedir que aqueles indivíduos propensos ao crime acabem incorrendo em uma conduta típica, desta feita a Teoria coloca ênfase no processo educativo da sociedade.

Já a Teoria da Prevenção Geral em sentido positivo, acredita que a pena não deve ser vista simplesmente como um meio de intimidar a sociedade; acreditam os adeptos desta Teoria ser a pena o resultado da eficaz efetivação da Justiça, fazendo com que sua aplicação consiga, não só cristalizar a vigência da norma jurídica, mas também moldar na sociedade o senso de certo e errado.

A prevenção geral em sentido positivo ainda se subdivide nas correntes Fundamentadoras e Limitadoras. A respeito destas ensina-nos Shecaira e Correa Junior (2002, p. 132):

A prevenção geral positiva limitadora contrasta com a fundamentadora na medida em que define a finalidade da pena, acrescentando um sentido limitador ao poder punitivo do Estado. Enquanto para a teoria fundamentadora o fim pretendido com a imposição da pena é, unicamente, a confirmação da norma e dos valores nela contidos, para a teoria limitadora esta finalidade da pena deve ser restringida pelos princípios da intervenção mínima, da proporcionalidade, da ressocialização, da 
culpabilidade etc. $\mathrm{O}$ direito de punir do estado não pode ir além desses princípios, sob pena de se tornar arbitrário, impondo, de maneira coativa, determinados padrões éticos.

Acreditamos ser a corrente Fundamentadora a aplicação simples da Teoria da Prevenção Geral Positiva, onde o objetivo é a efetivação da norma jurídica, bem como a criação de uma consciência social, da existência de valores fundamentais a serem seguidos por todos. Já a corrente Limitadora, busca este mesmo fim, porém acredita que deva existir uma ponderação entre a aplicação da norma e o efeito que está irá causar, para que o direito de punir do Estado não se torne coercitivo em excesso.

Ainda dentro do leque das Teorias Relativas encontramos a corrente da Prevenção Especial; os adeptos desta acreditam que o principal objetivo da pena é evitar a reincidência do condenado na prática criminosa; sendo está ainda subdividida em dois aspectos, um negativo, que almeja o objetivo através da prisão do infrator, e outro positivo, que busca sua finalidade por meio da reinserção social.

Com o objetivo de unificar as finalidades retributivas e preventivas das penas surgiram as Teorias Mistas ou
Ecléticas. Enio Luiz Rossetto as aborda em sua obra desta forma (2014, p. 78):

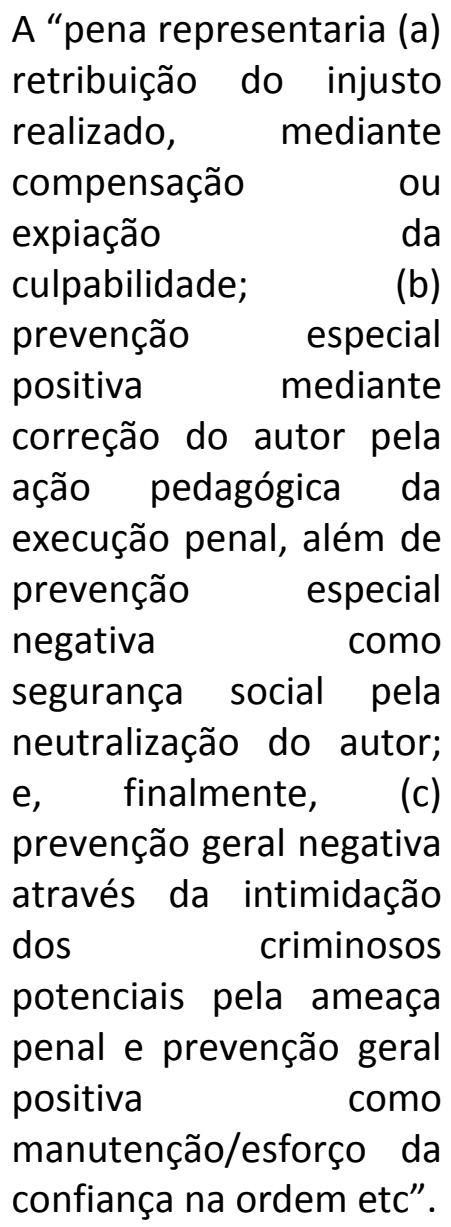

A legislação brasileira seguindo uma tendência mundial adotou o sistema das Teorias Mistas ou Ecléticas em sua legislação.

\section{O Sistema Prisional}

O Brasil adotou em suas penitenciarias o sistema progressivo, que consiste no inicio do cumprimento da pena por um estágio mais gravoso seguido de sua progressão para estágios menos gravosos, na medida em que o detendo vai criando aptidão para tanto seja ela de ordem objetivo ou subjetiva, até que este se apresente apto ao convívio social. 
A palavra "penitenciaria" tem origem nos mosteiros antigos, onde os monges que cometiam alguma infração deviam se isolar em seu claustro para orar e meditar sobre seu erro.

É evidente que atualmente nosso sistema prisional está longe de cumprir o seu papel, visto que este não pune e muito menos reintegra os detentos.

Os presídios estão superlotados e sucateados, os presos em regime fechado que deveriam ficar isolados no período noturno não o podem devido a superlotação, muitas vezes ficando junto a outros detentos de periculosidade elevada, o que os permite realizar durante o seu período de prisão o verdadeiro "curso" de crime.

Os sentenciados que muitas vezes alcançam o direito de progredir para 0 regime semi-aberto, são postos diretamente em regime aberto por falta de vagas nas Colônias Agrícolas e Industriais, pondo com isso um fim ao objetivo do sistema de progressão; um estudo realizado em parceria com o CNJ e IPEA estima que a reincidência no Brasil varie de $30 \%$ a $70 \%$, dependendo qual conceito de reincidência será aplicado; o fato é que a falência do sistema prisional denunciada por Beccaria em 1764 não foi sanada até os dias de hoje:

Beccaria, Dos delitos e das penas. Tradução ANGELIS, (1993. p. 23):
É porque o sistema atual da jurisprudência criminal apresenta aos nossos espíritos a idéia da força e do poder, em lugar da justiça; é porque se lançam, indistintamente, na mesma masmorra, o inocente suspeito e o criminoso convicto; é porque a prisão, entre nós, é antes um suplício que um meio de deter um acusado [...].

Sem dúvida é de se assustar a atualidade do posicionamento de Cesare Beccaria, em sua obra, acima citada, mesmo tendo sido este escrito ainda no século dezoito. Tornando-se mais um convincente motivo para que se repense a redução da maioridade penal, visto que a realidade de nossas prisões são justamente estes ditas acima, nas quais o "inocente suspeito e o criminoso convicto" encontram-se detidos no mesmo ambiente. Ainda devemos nos lembrar que ao ser questionado o atual Ministro da Justiça definiu o nosso sistema prisional da seguinte forma: "Temos um sistema prisional medieval que não é só violador de direitos humanos, ele não possibilita aquilo que é mais importante em uma sanção penal que é a reinserção social".

Fica então a pergunta, introduzir neste sistema os jovens infratores irá solucionar o problema da criminalidade 
infantil, o objetivo da teoria unificadora da pena adotado no Brasil será alcançado?

A resposta à pergunta só pode ser negativa; seria um erro de conseqüências inimagináveis inserir jovens infratores neste sistema, é necessário que se busque soluções alternativas, como será demonstrado ao longo do estudo.

\section{As Penas Atuais Destinadas aos Menores}

Nos últimos tempos, de uma forma até irresponsável foi propagado em nosso meio social que os menores infratores não são punidos de maneira eficiente ou muitas vezes nem o são. Na verdade o objetivo das penalidades aplicadas a estes jovens deveria ser sempre no sentido de reeducar e não simplesmente punir por punir.

Vamos analisar afundo como 0 Estatuto da Criança e do Adolescente trata este tema e sobre tudo se as disposições desta importante Lei vêm de fato sendo cumpridas.

Por uma simples razão eufêmica as condutas cometidas por menores que contrariam a legislação não são chamadas de crimes mais sim de atos inflacionais, o artigo 103 do ECA define-o com a seguinte redação: "considera-se ato infracional a conduta descrita como crime ou contravenção penal."

Esta redação é de suma importância, pois demonstra sem sombra de dúvidas que os menores são punidos se cometerem qualquer conduta típica, assim como são os adultos. Portanto não a que se falar em impunidade generalizada.

Quando um menor comete algum ilícito fica sujeito a uma serie de medidas sócio-educativas, tais como: prestação de serviço a comunidade, liberdade assistida, obrigação e reparar o dano e a mais conhecida delas, a internação.

A internação consiste no recolhimento do infrator a um estabelecimento educacional adequado, por prazo indeterminado devendo a manutenção ser reavaliada no prazo máximo de seis meses, dentro de um limite que não pode ultrapassar três anos.

O ECA ainda determina a obrigatoriedade da aplicação de medidas pedagógicas para os adolescentes durante o período de internação, ainda que provisória, a reprimenda ainda deverá ser cumprida em estabelecimentos especiais diversos dos destinados a abrigo, seguindo rigorosos critérios de separação por idade, compleição física e gravidade da infração.

Fora o período de internação, cujo prazo máximo não pode ultrapassar três anos, se faz mister destacar a possibilidade de esgotado este prazo não estando o infrator totalmente ressocializado, a possibilidade de sua inserção no regime de semi-liberdade, que equivale ao semi-aberto do sistema punitivo de adultos. Por este 
sistema o interno poderá cumprir atividades externas de escolarização e profissionalização.

Passado por este dois sistemas acima citados o menor ainda poderá ser introduzido na Liberdade Assistida, que consiste no acompanhamento do infrator por pessoa capacitada, designada por autoridade que deverá prestar orientações a família e ao adolescente, bem como acompanhar sua freqüência escolar dentre outras atividades. A liberdade assistida tem prazo mínimo de seis meses, podendo se prorrogada sempre que necessário.

Encerrada esta explanação nos parece mais que vencido $o$ argumento da impunidade dos menores, e evidente que o problema da criminalidade infantil esta não na letra da lei, mas sim nos graves problemas estruturais que o país enfrenta.

Estes problemas ficam evidentes em uma recente pesquisa realizada pelo CNMP (Conselho Nacional do Ministério Público), que demonstrou como a ressocialização dos menores esbarra em típicos problemas do sistema prisional convencional, o estudo mostrou que em 15 estados mais o Distrito Federal, as unidades de internação estão superlotadas.

Segue abaixo os dados do estudo:

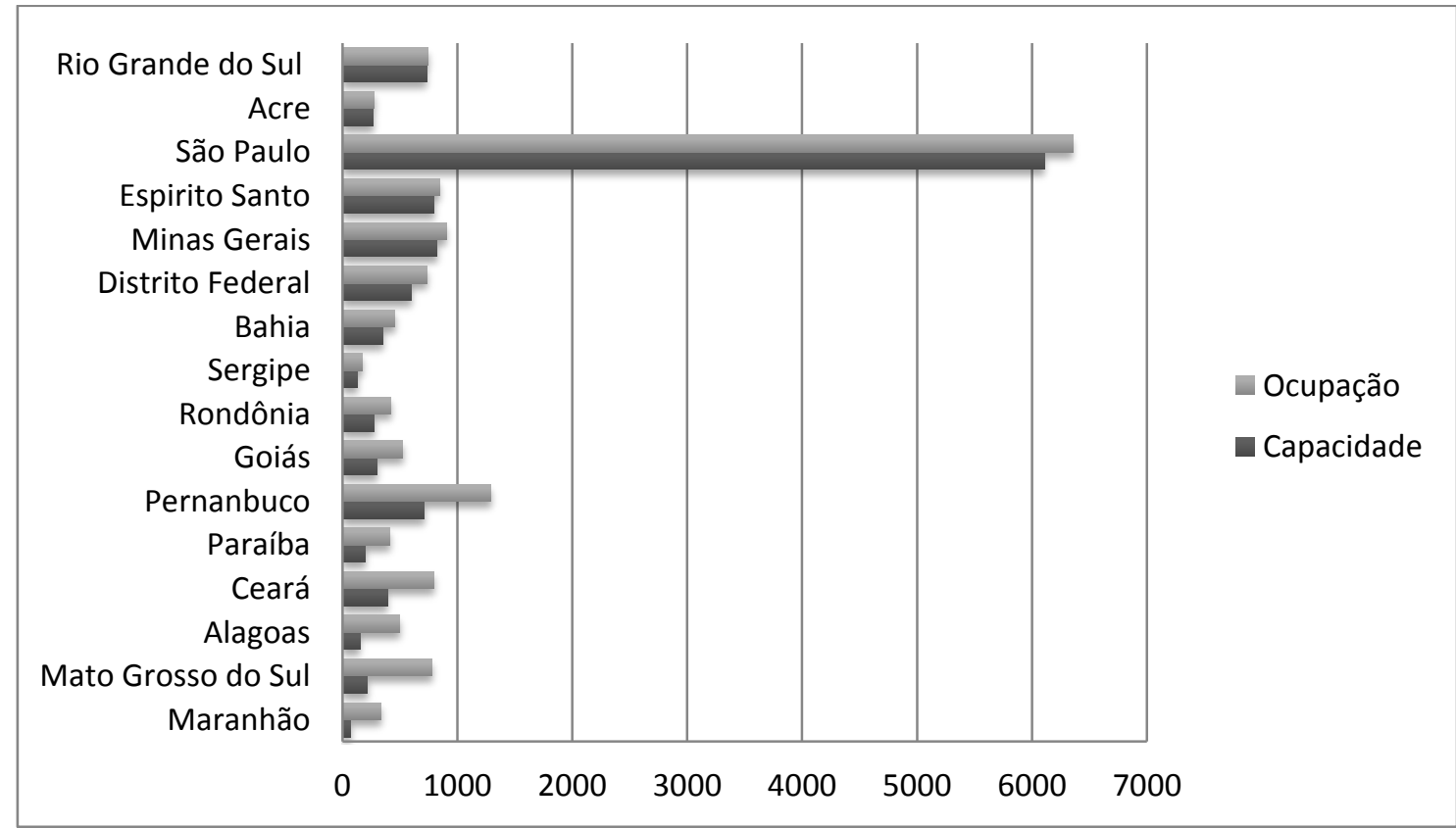

Gráfico 1. Estados Que Apresentam Superlotação em Seus Estabelecimentos de Internação. 


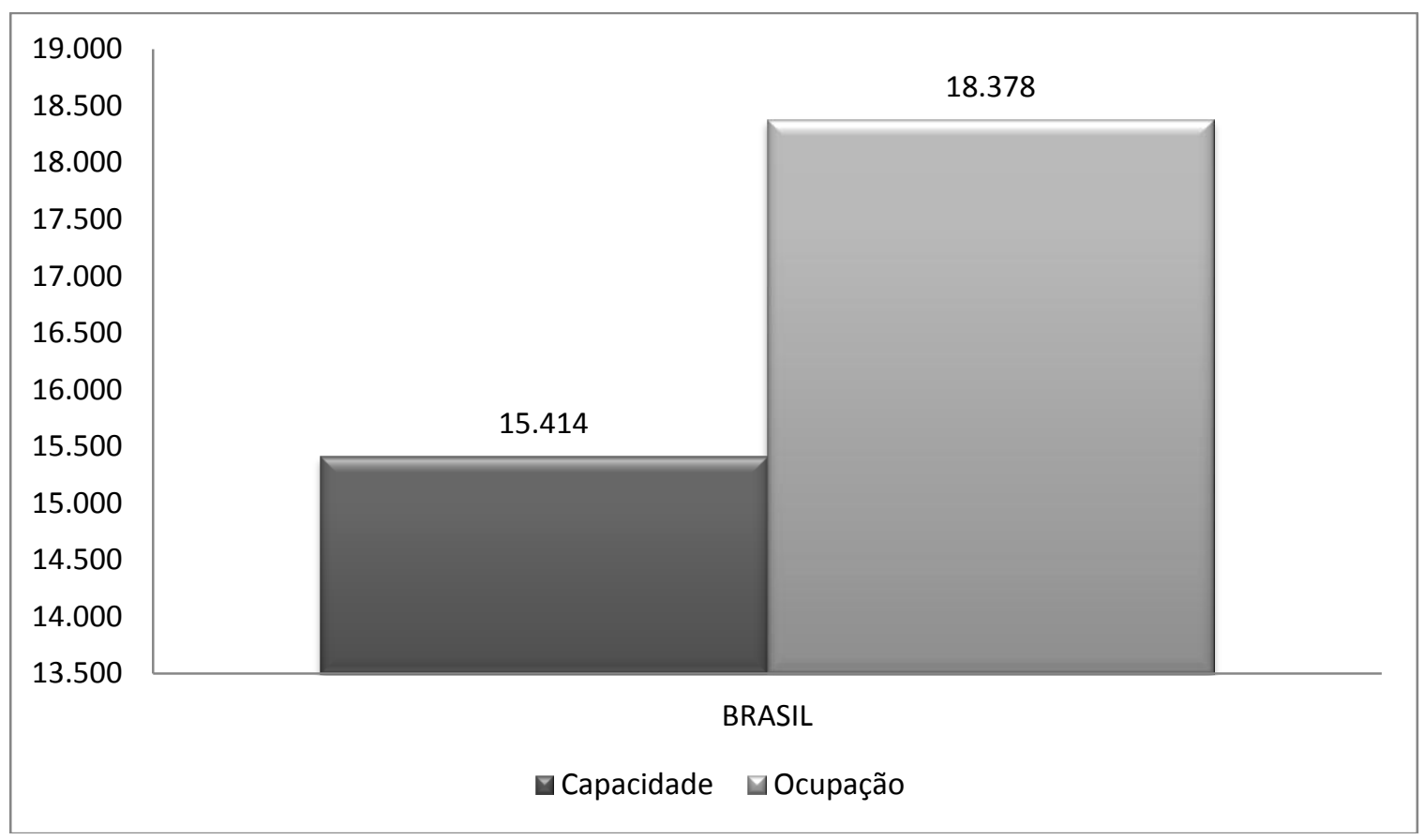

Gráfico 2. Déficit de Vagas nos Estabelecimentos de Internação no Brasil.

Além da superlotação dos estabelecimentos o estudo mostrou que um quinto dos infratores cumprem as medidas em unidades distantes da casa dos pais ou responsáveis, existe ainda uma profunda ausência de salas de aulas, espaços para cursos, ou áreas para desenvolvimento de esporte, cultura e lazer, como também desrespeito a regra de a separação dos internos por crime cometido, idade e até mesmo porte físico, permitindo desta forma que diferentes perfis de infratores convivam entre si. Se isto não basta-se, metade dos estabelecimentos inspecionados foram considerados insalubres.

O estudo também constatou a existência de superlotação nos estabelecimentos destinados ao sistema de semi-liberdade, segundo o CNMP existem
122 estabelecimentos desse tipo em funcionamento em todo país. A situação mais alarmante foi encontrada no estado de Alagoas onde em uma unidade com capacidade para atender 15 adolescentes havia 175 , um déficit de $1.166 \%$.

O estudo foi encerrado com um relatório que vai no sentido oposto daqueles que defendem a implementação de penas mais rigorosas para os menores infratores. De acordo com os responsáveis pelo estudo “limitar a problemática infracional ao debate sobre a redução da maioridade penal é, de todas e, de longe, a saída mais fácil e menos resolutiva".

Com a analise do estudo acima citado damos por encerrado o exame da atual legislação voltada ao menores infratores, 
bem como a forma como está vem sendo atualmente aplicada país a fora.

\section{A Maioridade Penal e o Direito Comparado}

Um argumento recorrente entre os que defendem a redução da maioridade penal é o de que na maioria dos outros países ela ocorre de forma mais precoce do que no nosso; talvez por desinformação ou até mesmo má-fé seja muito comum ver os defensores da redução apresentarem a idade de responsabilidade penal juvenil como se fossem os da maioridade penal nos outros países.

Ao contrário do que se argumenta, nos últimos tempos, tem ocorrido uma grande mobilização no sentido de fixar a maioridade penal acima dos dezoito anos,

Tabela 1. A Responsabilidade Penal Juvenil e Penal de Adultos Pelo Mundo

\begin{tabular}{ccc}
\hline Países & Responsabilidade Penal Juvenil & Responsabilidade Penal de Adultos \\
\hline Alemanha & 14 & $18 / 21$ \\
\hline Argentina & 16 & 18 \\
\hline Argélia & 13 & 18 \\
\hline Áustria & 14 & 19 \\
\hline Bélgica & $16 / 18$ & $16 / 18$ \\
\hline Bolívia & 12 & $16 / 18 / 21$ \\
\hline Bulgária & 14 & 18 \\
\hline Canadá & 12 & $14 / 18$ \\
\hline Colômbia & 14 & 18 \\
Chile & $14 / 16$ & 18 \\
China & $14 / 16$ & 18 \\
\hline Costa Rica & 12 & 18 \\
\hline Croácia & $14 / 16$ & 18 \\
\hline Dinamarca & 15 & $15 / 18$ \\
\hline El Salvador & 12 & 18 \\
\hline Escócia & $8 / 16$ & $16 / 21$ \\
\hline Eslováquia & 15 & 18 \\
\hline Eslovênia & 14 & 18 \\
Espanha & 12 & $18 / 21$ \\
\hline
\end{tabular}




\begin{tabular}{|c|c|c|}
\hline Estados Unidos & 10 & $12 / 16$ \\
\hline Estônia & 13 & 17 \\
\hline Equador & 12 & 18 \\
\hline Finlândia & 15 & 18 \\
\hline França & 13 & 18 \\
\hline Grécia & 13 & $18 / 21$ \\
\hline Guatemala & 13 & 18 \\
\hline Holanda & 12 & 18 \\
\hline Honduras & 13 & 18 \\
\hline Hungria & 14 & 18 \\
\hline $\begin{array}{c}\text { Inglaterra e Países de } \\
\text { Gales }\end{array}$ & $10 / 15$ & $18 / 21$ \\
\hline Irlanda & 12 & 18 \\
\hline Itália & 14 & $18 / 21$ \\
\hline Japão & 14 & 21 \\
\hline Lituânia & 14 & 18 \\
\hline México & 11 & 18 \\
\hline Nicarágua & 13 & 18 \\
\hline Noruega & 15 & 18 \\
\hline Países Baixos & 12 & $18 / 21$ \\
\hline Panamá & 14 & 18 \\
\hline Paraguai & 14 & 18 \\
\hline Peru & 12 & 18 \\
\hline Polônia & 13 & $17 / 18$ \\
\hline Portugal & 12 & $16 / 21$ \\
\hline República Dominicana & 13 & 18 \\
\hline República Checa & 15 & 18 \\
\hline Romênia & $16 / 18$ & $16 / 18 / 21$ \\
\hline Rússia & $14 / 16$ & $14 / 16$ \\
\hline Suécia & 15 & $15 / 18$ \\
\hline Suíça & $7 / 15$ & $15 / 18$ \\
\hline Turquia & 11 & 15 \\
\hline Uruguai & 13 & 18 \\
\hline Venezuela & $12 / 14$ & 18 \\
\hline
\end{tabular}

Além da apresentação dos dados acima, que representam todos os países estudados, dois casos específicos merecem destaque, o da Alemanha e Japão, o primeiro país chegou a reduzir a maioridade penal, mas não satisfeito com os resultados conseguidos, retornou ao patamar anterior de dezoito anos e ainda criou um sistema especifico de cumprimento de pena para os infratores entre dezoito e vinte um anos de idade; já o segundo ao começar a registrar um aumento da criminalidade juvenil, elevou a imputabilidade penal para vinte e um anos e voltou seus investimentos para políticas pedagógicas

Este posicionamento majoritário decorre de recomendações internacionais no sentido de que os países fixem um sistema 
diferenciado para processar e julgar os infratores que possuam idade inferior a dezoito anos, ou seja, está mais que cristalizada a corrente mundial no sentido de implantar legislações e justiças especializadas para processar e julgar os menores de dezoito anos que venham a infringir o ordenamento jurídico.

Como se pode perceber se nosso país quiser mesmo seguir tendência mundial, o caminho para enfrentar a criminalidade juvenil será a manutenção da maioridade penal aos dezoitos anos, seguido de fortes investimentos na área pedagógica.

\section{A Violação e Clausula Pétrea e a Afronta a}

\section{Compromissos Internacionais}

É notório que qualquer tentativa de se retirar o tratamento constitucional diferenciado aos menores de dezoito anos que venham a se envolver em ilícitos estará afrontando toda a principiologia constitucional.

É consenso em todo mundo jurídico tratar-se de direito individual de todo adolescente ser tratado por uma legislação especial, diferenciada da destinada aos adultos. Desta feita é impossível que o poder constituinte derivado consiga abolir ou mesmo restringir este sistema. $\mathrm{O}$ fato de a maioridade penal aos dezoitos anos estar prevista fora do texto do artigo $5^{\circ}$ da Carta da República é um argumento que não se sustenta, já que o próprio Supremo Tribunal Federal já admitiu a existência de outros direitos individuais espalhados pelo texto constitucional.

Neste sentido ensina-nos Luiz Roberto Barroso (Curso de Direito Constitucional Contemporâneo, 2013 p. 199/200):

[...] Pelo próprio Supremo Tribunal Federal. Em decisão que se tornou histórica [...] o Tribunal adotou posição ousada e louvada: a de que existem direitos protegidos pela cláusula do inciso IV do $\S 4^{\circ}$ do art. 60 que não se encontram expressos no elenco do art. $5^{\circ}$ inclusive notadamente por força de seu $\S 2^{\circ}$.

Já sendo o explanado acima mais que suficiente para firmar o posicionamento aqui defendido, ainda temos os artigo 34, inciso VII, alínea " $b$ ", onde encontramos os direitos da pessoa humana como princípio auxiliar para fundamentar esta corrente de pensamento.

Fora já o debatido, ainda cabe-nos lembrar que a redução da imputabilidade penal para patamares inferiores a dezoito anos estará indo em confronto com diversos compromissos internacionais assumidos pelo Brasil visto que os direitos presentes nestes tratados possuem força constitucional por 
determinação do artigo $5^{\circ}$, parágrafo $2^{\circ}$ da Constituição da República.

A Alteração do Estatuto da Criança e do Adolescente como Pacificador Social

No debate a respeito da redução da maioridade penal dois pontos não podem passar ausentes da analise dos defensores de sua manutenção nos patamares atuais, a atual sensação de impunidade que paira no imaginário da população como também a existência de casos excepcionais que merecem sim um tratamento diferenciado do atual.

Uma solução equilibrada para estes dois problemas seria sem dúvida a modificação do Estatuto da Criança e do Adolescente, visto que em alguns casos específicos o período de internação máximo de três anos têm-se mostrado insuficiente.

Nesse diapasão nos parece bem adequado o projeto de Lei $n^{\circ} 333 / 2015$, de autoria do Senador paulista José Serra, que cria um Regime Especial de cumprimento de pena para aqueles adolescentes que cometam atos infracionais equivalentes a crimes hediondos, no qual o período de internação poderá ser estendido por um prazo de até dez anos. Além de determinar que o menor continue internado em estabelecimento especial mesmo que venha a completar dezoito anos durante seu período de internação.
O referido projeto já foi aprovado no Senado da República e nos parece uma solução racional e viável para o problema com o qual nos deparamos, nenhuma norma constitucional será infringida, conseguiremos tratar com mais rigor os adolescentes que apresentem periculosidade elevada e por fim será dada uma resposta a sociedade que anseia por mudanças no Estatuto.

É importante destacar que esta mudança em nada surtirá efeito se os graves problemas estruturais pelos quais passam as unidades de internação país a fora não sejam sanados, como aqui já foi demonstrado.

\section{A Solução de Longo Prazo: Educação}

O Conselho Nacional de Justiça realizou recentemente um estudo com o objetivo de traçar um panorama geral dos menores infratores do país. Os resultados do estudo só vieram a atestar a argumentação daqueles que defendem o investimento em educação como forma de combater a criminalidade juvenil.

O estudo apontou que a maior parte dos infratores juvenis comete seu primeiro ato infracional aos quinze anos de idade, sendo que metade destes abandonou os estudos aos quatorze anos. O dado mais alarmante do levantamento é o de que $90 \%$ desses adolescentes não vêem sequer a concluir o ensino fundamental. 
Dados como estes são fundamentais para que se possam traçar estratégias eficazes de combate a criminalidade infantojuvenil, enviar um adolescente para um presido não é somente desumano, mas sim, retrogrado, incoerente e inconsequente, considerar um menor infrator como irrecuperável beira as raias da estupidez. Prevenir sempre será melhor que remediar, educar sempre será mais eficaz do que punir.

A educação e a cultura não devem ser somente destinadas para solucionar a criminalidade infantil mais sim também a sociedade como um todo, para que esta se conscientize das consequenciais gravosas que uma eventual redução da maioridade penal implicaria, bem como para que esta saiba se informar adequadamente a respeito dos números e dados que orbitam este assunto. Com isto sem dúvida o apoio popular a este tema irá se reduzir de maneira considerável.

\section{CONCLUSÕES}

É evidente que o apoio a redução da maioridade penal cresce a cada dia no seio da sociedade em geral, mas isto só ocorre pelo fato de esta não ser corretamente

\section{REFERÊNCIAS}

BARROSO, R, L. Limites Materiais. In:

BARROSO, R, L. Curso de direito

constitucional contemporâneo. São Paulo:

Saraiva, 2013. p. 182-205. informada acerca das conseqüências que isto implicaria, bem como sobre os verdadeiros dados que circundam este debate.

É fundamental que os defensores da manutenção da proteção constitucional aos menores de dezoito anos não se calem diante daqueles que por desinformação insistem nesta abominação legal, caso o parlamento caia neste erro estaremos condenando as futuras gerações a um quadro de insegurança pública ainda mais alarmante do que este que vivemos atualmente.

Acreditamos que os dados aqui apresentados são mais que suficientes para demonstrar que na prática o Estatuto da Criança e do Adolescente não é aplicado corretamente, portanto não a que se falar em ineficiência da Lei.

$$
\text { É preciso que o país encare a }
$$
realidade que o cerca e enfrente o problema de frente não buscando a solução fácil, mas sim a eficaz; não existe outro caminho para combater a criminalidade juvenil no Brasil, que não seja a correção dos problemas estruturais que enfrentam as unidades de internação, bem como um maciço investimento em educação.

BECCARIA, C, B. Da Prisão. In: BECCARIA, C. B. Dos delitos e das penas. Tradução ANGELIS, F. Bauru: Epidro, 1993. p. 23-24. 
GRECO, R. Das penas. In: GRECO, R. Curso direito penal parte geral. 14. ed. Rio de Janeiro: Impetus, 2012. p. 470-474.

ROSSETTO, L. E. Fundamentos da Pena. In: ROSSETTO, L. E. Teoria e aplicação da pena. São Paulo: Atlas, 2014. p. 43-81.

SHECAIRA, S.; CORRÊA JUNIOR, A. A Finalidade da Sanção Penal. In: SHECAIRA, S.; CORRÊA JUNIOR, A. Teoria da pena: finalidades, direito positivo, jurisprudência e outros estudos de ciência criminal. São Paulo: Revista dos Tribunais, 2002. p. 128137.

BRASIL. Brasil tem déficit de quase $3 \mathrm{mil}$ vagas para acolher jovens em conflito com a lei, RODRIGUES, A. Disponível em: shttp://memoria.ebc.com.br/agenciabrasil/n oticia/2013-08-08/brasil-tem-deficit-dequase-3-mil-vagas-para-acolher-jovens-emconflito-com-lei $\geq$. Acesso em: 24 jul. 2015.

BRASIL. Congresso Nacional. Estatuto da Criança e do Adolescente. Lei ${ }^{\circ} 8.069$ de 13 de julho de 1990. Dispõe sobre o estatuto da criança e do adolescente e dá outras providencias. Diário Oficial da União, Brasília, DF, 13 jul. 1990. Disponível em: $\leq$ http://www.planalto.gov.br/CCIVIL_03/leis/L 8069.htm . Acesso em: 25 jul. 2015.

Fundo das Nações Unidas para a Infância. Porque dizer não a redução da maioridade penal; Sposato, B, P, 2007. Disponível em: $\leq$ http://www.crianca.mppr.mp.br/arquivos/F ile/idade_penal/unicef_id_penal_nov2007_c ompleto.pdf $\geq$. Acesso em: 19 jul. 2015.
FURLAN, F, L. Inconstitucionalidade da redução da maioridade penal. Colloquium humanarum, Presidente Prudente, v.11,n. especial,. Jul./dez., 2014. Disponível em: shttp://www.unoeste.br/site/enepe/2014/su plementos/area/Humanarum/Direito/INCON STITUCIONALIDADE\%20DA\%2OREDU\%C3\%87 \%C3\%830\%20DA\%20MAIORIDADE\%20PENA L.pdf $\geq$. Acesso em: 20 jul. 2015.

INSTITUTO DE PESQUISA ECONÔMICA APLICADA. Reincidência Criminal no Brasil; 2015. Disponível em: shttp://www.ipea.gov.br/portal/images/stori es/PDFs/relatoriopesquisa/150611_relatorio _reincidencia_criminal.pdf $\geq$. Acesso em: 19 jul. 2015.

RELATÓRIO DA INFÂNCIA E JUVENTUDE Resolução no 67/2011: Um olhar mais atento às unidades de internação e semiliberdade para adolescentes. Brasília: Conselho Nacional do Ministério Público, 2013. Disponível em: $\leq$ http://www.crianca.mppr.mp.br/arquivos/Fil e/publi/cnmp/relatorio_res_67_internacao_v 1.pdf $\geq$. Acesso em: 20 jul. 2015.

Recebido para publicação em 16/08/2015 Revisado em 01/09/2015 Aceito em 04/09/2015 